\section{Biomasfor: an open-source holistic model for the assessment of sustainable forest bioenergy}

\author{
Sandro Sacchelli ${ }^{(1)}$, Pietro Zambelli ${ }^{(2)}$, Paolo Zatelli ${ }^{(2)}$, Marco Ciolli ${ }^{(2)}$
}

This paper presents an open-source spatial analysis model (Biomasfor) that can quantify the availability of forest wood-energy biomass in the light of ecological and economic sustainability. Several multi-functionality parameters were evaluated to highlight the potential impact of biomass extraction on different forest functions. The multistep approach used and the model's internal structure permit the use of the model with highly differentiated input datasets. The introduction of biomass demand evaluation allows the quantification of the wood-energy supply/demand. The analysis is focused on the province of Trento (northeastern Italian Alps). The results are based on a scenario evaluation characterised by several degrees of biomass extraction and by a sensitivity analysis of biomass price, as well as on a typology of mechanisation. The model outputs define a reduction in biomass availability with the introduction of technical, economic and multi-functionality parameters. Furthermore, considerations on territorial characteristics outline the importance of woodchip production as a means of avoiding carbon dioxide emissions and achieving low-impact reductions of the risk of fires. The model appears to be an effective tool in bioenergy planning, particularly for the following purposes: (i) the estimation of the biomass supply/demand ratio under different scenarios; (ii) a preliminary analysis of biomass quality; and (iii) the influence of local environmental, economic and logistical characteristics on biomass production.

Keywords: Spatial Analysis, Bioenergy, Open Source, Forest Multi-functionality, Holistic Models, GIS

\section{Introduction}

The assessment of the agroenergy chain is a fundamental issue in the field of renewable energies, in particular for the substitution of alternative energy sources for fossil fuels in rural areas (Fiorese \& Guariso 2010). In this framework, the relevant topics are the evaluation of the bioenergy demand/supply ratio and the quantification of the impact of biomass on ecological and socio-economic parameters (Steubing et al. 2010). Furthermore, the evaluation of the agroenergy chain must consider policy directives and the presence of fundings and regulation that can cause market distortion (Sonneborn 2004).

(1) GESAAF - Dipartimento di Gestione dei Sistemi Agrari, Alimentari e Forestali, Univ. di Firenze, p.le delle Cascine 18, I-50144 Florence (Italy); (2) DICAM - Dipartimento di Ingegneria Civile, Ambientale e Meccanica, Università di Trento, v. Mesiano 77, I-38123 Trento (Italy)

\section{@ Sandro Sacchelli (sandro.sacchelli@unifi.it)}

Received: Nov 16, 2012 - Accepted: Apr 02, 2013

Citation: Sacchelli S, Zambelli P, Zatelli P, Ciolli M, 2013. Biomasfor - an open-source holistic model for the assessment of sustainable forest bioenergy. iForest 6: 285-293 [online 2013-07-01] URL: http://www.sisef.it/iforest/contents/?id=ifor0897-006

Communicated by: Luca Salvati (e.g., for a widespread relationship linking the agroforestry environment with the local population - Ramachandra 2009, Notaro \& Paletto 2011). The variability of national forest areas in terms of geomorphology, species composition, facilities and socio-economic issues requires the use of flexible tools and Decision Support Systems (DSSs) to quantify the resources and to facilitate the communication between researchers, local stakeholders and policy makers in woodenergy planning activities as applied to the forest sector. A Geographic Information Systems (GIS) approach appears to represent an appropriate tool for attaining this goal.

Several studies have analysed GIS and spatial analysis instruments as tools for biomass chain evaluation at the European, national and local levels. Angelis-Dimakis et al. (2011) classify energy availability in terms of potential availability (according to the gross energy of the source), theoretical availability (the harvestable fraction) and exploitable availability (based on ecological and economic sustainability criteria).

A state-of-the-art treatment of the topic of forest biomass availability at the European level was developed by Rettenmaier et al. (2008) who analysed the methodological approaches and input datasets used for bioenergy estimation. These authors classified the analytic process according to biomass typology (ecological, technical, economical, sustainable), biomass sources (e.g., residues, stem, stumps) and spatial-temporal variables (e.g., scale of analysis, time frame). Geomatic applications for biomass resource evaluation have been implemented by different authors (Chirici et al. 2007, Lasserre et al. 2011, Kotamaa et al. 2010). For example, Gallaun et al. (2010) have combined national forest inventory data and remotely sensed data to estimate the total increment and the above-ground biomass at the European level. The advantages and disadvantages of the application of geomatic procedures to bioenergy quantification have been analysed by Calvert (2011).

Several studies consider the optimal location/allocation of resources, based primarily on economic and logistic parameters but also on policy constraints and sustainability evaluations (Voivontas et al. 2001, Venema \& Calamai 2003, Moller \& Nielsen 2007, Panichelli \& Gnansounou 2008, Aguilar 2009, Frombo et al. 2009, Lopez-Rodrìguez et al. 2009, Aosić et al. 2011). Bush (2012) by the use of multi-criteria evaluation and linguistic variables, introduces regional stakeholder preferences and planning guidelines as allocation criteria for Short Rotation Coppices (SRC).

Verkerk et al. (2011) evaluated the potential supply of woody biomass from the forests of the EU in the light of multiple envi- 
ronmental, technical and social constraints These calculations were based on the $\mathrm{Na}$ tional Forest Inventories data implemented in the EFISCEN model. The quantification of the biomass supply/demand ratio has been achieved through widespread use of the calculations provided by the Woodfuel Integrated Supply/Demand Overview Mapping (WISDOM) approach (Masera et al. 2006).

The extraction of biomass components from forest areas (both the major components of the biomass - e.g., the stems - and other types of wood material - e.g., residues and stumps) has an impact on multifunctionality. This impact can be positive or negative depending on the local site characteristics (e.g., vegetation typology, geomorphology), silvicultural management and type of mechanisation. Berg et al. (2012) developed a tool for sustainability impact assessment (ToSIA) of the whole forest wood chain, including economic, social and environmental indicators. Among the variety of possible influences resulting from such biomass extraction, the possible positive impacts include fire prevention, risk management and forest

Tab. 1 - General input dataset and variable characteristics. (M): mandatory; (O): optional.

\begin{tabular}{|c|c|c|c|}
\hline Variable & Description & $\begin{array}{l}\text { Variable } \\
\text { typology }\end{array}$ & $\begin{array}{l}\text { Name of } \\
\text { attribute } \\
\text { column }\end{array}$ \\
\hline DTM (M) & Digital Terrain Model & ASCII GRII & - \\
\hline Main roads $(\mathrm{M})$ & Main roads features & Shapefile & m_road \\
\hline Forest roads $(\mathrm{M})$ & Forest roads features & Shapefile & f_road \\
\hline Total yield (M) & $\begin{array}{l}\text { Prescribed yield or periodic/annual } \\
\text { increment }\left(\mathrm{m}^{3}\right)\end{array}$ & Shapefile & yield \\
\hline $\begin{array}{l}\text { Yield of forest typology } \\
n(\mathrm{M})\end{array}$ & $\begin{array}{l}\text { Prescribed yield for forest } \\
\text { typology } n\left(\mathrm{~m}^{3}\right)\end{array}$ & Shapefile & vol_typoln \\
\hline Forest management $(\mathrm{M})$ & (1): high forest; (2): coppice & Shapefile & management \\
\hline $\begin{array}{l}\text { Woodchip collection } \\
\text { point(s), e.g., District } \\
\text { Heating Plants (DHP, M) }\end{array}$ & Woodchip collection point & Shapefile & dhp \\
\hline Landing site $(\mathrm{O})$ & Localization of landing sites & Shapefile & landing \\
\hline Forest treatment $(\mathrm{O})$ & 1: final felling, 2 : thinning & Shapefile & treatment \\
\hline Compartments $(\mathrm{O})$ & Compartments boundary & Shapefile & compartment \\
\hline Roughness (O) & $\begin{array}{l}\text { Roughness classification - (0): no } \\
\text { rugged; (1): locally rugged; }(2) \text { : par- } \\
\text { tially rugged; }(3) \text { : prevalently rugged }\end{array}$ & Shapefile & roughness \\
\hline Lakes $(\mathrm{O})$ & Lakes features & Shapefile & lake \\
\hline Rivers $(\mathrm{O})$ & Rivers features & Shapefile & river \\
\hline Mean tree diameter $(\mathrm{O})$ & Average diameter $(\mathrm{cm})$ & Shapefile & tree_diam \\
\hline Mean tree volume $(\mathrm{O})$ & Average single tree volume $\left(\mathrm{m}^{3}\right)$ & Shapefile & tree_vol \\
\hline Boundary $(\mathrm{O})$ & $\begin{array}{l}\text { Area to compute output variables } \\
(1,2, \ldots, m-, e . g ., \text { Regions, Province, } \\
\text { Municipality, etc })\end{array}$ & Shapefile & boundary \\
\hline Energy demand $(\mathrm{O})$ & $\begin{array}{l}\text { Annual bioenergy demand in DHP } \\
(\mathrm{MWh} / \mathrm{y})\end{array}$ & Shapefile & energy_dem \\
\hline Soil productivity (O) & $\begin{array}{l}\text { Soil fertility category - (1): very low; } \\
\text { (2): low; (3): medium; (4); high; (5): } \\
\text { very high }\end{array}$ & Shapefile & soil_prod \\
\hline Soil texture $(\mathrm{O})$ & $\begin{array}{l}\text { Soil texture category - }(1) \text { : not com- } \\
\text { pacted; }(2) \text { : medium compacted; }(3) \text { : } \\
\text { compacted }\end{array}$ & Shapefile & soil_text \\
\hline Soil depth $(\mathrm{O})$ & $\begin{array}{l}\text { Soil depth category - (1): superficial; } \\
\text { (2): medium deep; (3): deep }\end{array}$ & Shapefile & soil_depth \\
\hline Soil compaction risk $(\mathrm{O})$ & $\begin{array}{l}\text { Soil compaction risk category - (1): } \\
\text { low; (2): medium; (3): high; (4): very } \\
\text { high; (9): no evaluation }\end{array}$ & Shapefile & comp_risk \\
\hline Fire risk index $(\mathrm{O})$ & Fire risk index & Shapefile & fire_risk \\
\hline Protected areas $(\mathrm{O})$ & $\begin{array}{l}\text { Boundaries of protected areas: Natio- } \\
\text { nal, regional and provincial parks and } \\
\text { reserves, and Natura } 2000 \text { sites (value } \\
1 \text { for protected areas, } 0 \text { otherwise) }\end{array}$ & Shapefile & protected \\
\hline Touristic value $(\mathrm{O})$ & $\begin{array}{l}\text { Suitability for recreational and tou- } \\
\text { ristic activity (value } 1 \text { for suitable } \\
\text { areas, } 0 \text { otherwise) }\end{array}$ & Shapefile & touristic \\
\hline
\end{tabular}

health (Raison 2002, Soliño et al. 2010), greenhouse gas (GHG) emissions reduction (Wang et al. 2010, Valente et al. 2011) and the addition of touristic-recreational value (Ribe 1989, Stupak et al. 2010). In contrast, an analysis of the literature stresses that negative impacts can potentially arise in the areas of soil fertility reduction (Eisenbies et al. 2009, Wall \& Hytönen 2011, Aherne et al. 2012), decreased soil and water protection (Abbas et al. 2011, Aherne et al. 2012) and biodiversity losses (Riffell et al. 2011, Sullivan et al. 2011). Therefore, in a complex system such as the forest environment, it is important to evaluate the impact of biomass removal to prevent the overestimation of the bioenergy supply.

The general background developed for the analysis of applied GIS DSSs in the biomass sector stresses that the majority of the above mentioned papers refer to specific objectives and study areas. The application of these models to other case studies could be difficult because of differences in the datasets available. In addition, the model structure could complicate the implementation and evaluation of new variables and parameters, in particular if the model is based on proprietary software (Steinigera \& Hay 2009).

From this perspective, the implementation of the so-called holistic models (HMs) including the assessment of the bioenergy sector could be an intriguing new line of research. HMs focussed on bioenergy chain decision support and planning are not common in the literature. Among the case studies developed in recent years at the national level, an example of integration between landscape planning and the evaluation of bioenergy has been implemented through the PANDORA model (Gobattoni et al. 2011). This model is able to incorporate concepts of thermodynamics, mathematical equilibrium and landscape analysis. The application of HMs requires the inclusion of a large number of parameters in the decision-making process; therefore, it is necessary to find a trade-off among the objectives of the analysis, the uncertainty allowable of the results and the feasibility of implementation of different scenarios.

In this framework, an open-source spatial analysis model (Biomasfor) that successfully overcomes the abovementioned limits will be specified. In the following paragraph, the model background will be examined. The characteristics of the Biomasfor model and an illustrative case study will then be presented.

\section{Model background and integration of new components}

The first version of the Biomasfor model was developed by Zambelli et al. (2012). Their study implemented an estimate of the technical biomass extracted by a ground- 


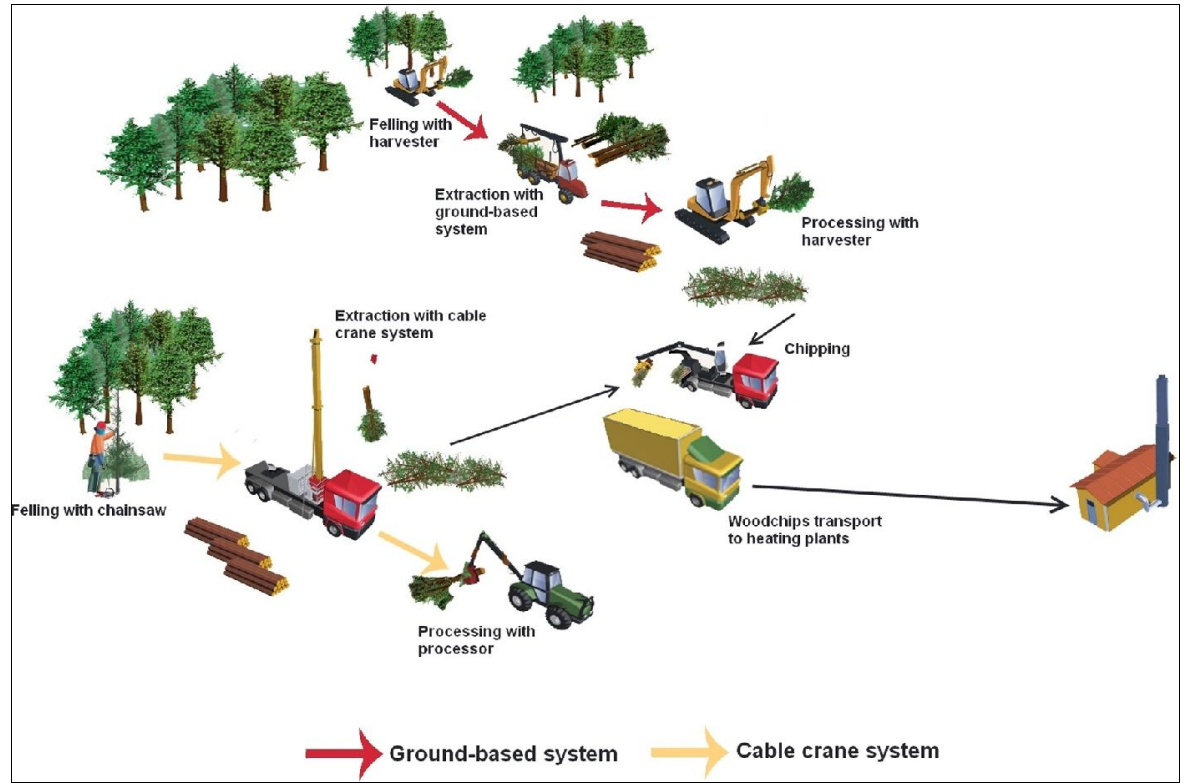

Fig. 1 - Example of forest production chain in high forests (source: http://www.forestenergy.org/pages/images/ - Forest Energy Portal 2012, modified)

based and cable crane system. The model computes the forest biomass with an approach based on the Free and Open Source Software for Geospatial (FOSS4G) framework (Zambelli et al. 2010). In the first version, the methodology combined the opensource GRASS software, PostGIS and the PostgreSQL object-relational database management system. In the present study, Biomasfor was implemented with economic and forest multifunctionality parameters following the approach used in Sacchelli et al. (2013a) and in Sacchelli et al. (2013b), respectively. In these two papers, the spatial analysis was based on proprietary software. To facilitate the installation of the software, the management of the tool and future development, the new Biomasfor version is based exclusively on GRASS GIS v. 7.0 (Neteler et al. 2012).

\section{Model implementation}

\section{Preliminary step}

The Biomasfor model calculates the supply of forest energy-biomass for a defined territory.

Depending on the completeness of the input database available to the user, the model conducts a multi-step analysis that can yield estimates of ecological, technical, economic and sustainable bioenergy. By "ecological bioenergy", we mean bioenergy based on a prescribed yield (e.g., in a Forest Management Plan) or on a periodic/annual increment (e.g., in a Forest Inventory). "Technical bioenergy" considers woody biomass obtained from a forest surface where extraction is possible given a particular level of mechanisation. The "economic bioenergy" is the part of the technical bioenergy that can be collected to supply heating plants or biomass logistic centres and that is associated with a positive net revenue for the entire production process. Finally, "sustainable bioenergy" introduces multifunctionality parameters and limits for biomass production.

The first step in model implementation is the dataset integration. Biomasfor automatically imports all variables according to the assigned column name (when variables are in shape file format - Tab. 1) and transforms them into a raster map with a specified pixel resolution. The input variable can be classified as mandatory (parameters strictly necessary for running the model) or optional. If the value of an optional variable is not available, a default value is used. This approach allows the model to process data even if certain parameter values are not available.

Each of the categorised bioenergy typologies (ecological, technical, economic and sustainable) represents a Biomasfor submodel, as described in the following paragraphs.

\section{Sub-models}

\section{Ecological bioenergy quantification}

Biomasfor calculates ecological availability depending on yield, forest management and forest treatment. In the case of final felling or when the forest treatment typology is not specified, the total biomass is evaluated as a percentage of the prescribed yield expressed as cormometric volume (bark and stem without tops and branches). In the case of thinning intervention, the total bioenergy is derived from the whole tree (tops and branches, as well as the stem or a percentage of the stem). The analysis of field operations emphasises that the thinning of coppices is generally economically disadvantageous; therefore, only residues can be included in the computations included in the bioenergy calculations under this forest management approach.

Total bioenergy is finally quantified as the result of final fellings or on an annual basis according to the rotation period.

\section{Technical bioenergy quantification}

The model considers two types of forest processes: a ground-based extraction system and cable crane extraction (Fig. 1). The basis of the model is that the production of forest biomass is economically feasible with the Full Tree System (FTS) both in high forests and in coppices, in particular for the processing of tops and branches (Spinelli \& Magagnotti 2007).

The mechanisation of extraction depends on the distance from the landing site, the slope and the terrain roughness as described in Zambelli et al. (2012) and specified in the following case study. The integration of Biomasfor introduces additional forest chain organisation for thinning treatments and allows the parameter limits and the machinery typology to vary. The model can identify natural morphologies, such as morphometric features (e.g., pits, ridges, peaks), lakes and rivers, to calculate the actual extraction distances with the r.cost GRASS module. Full trees are extracted from the forest and delivered to the nearest landing site. Then, non-commercial material was chipped. Eventually, woodchips are delivered to their final destination (e.g., heating plants) by truck. In each evaluation unit (e.g., forest compartment), technical bioenergy can be considered to be spread uniformly over the entire surface or to be concentrated in accessible areas.

\section{Economic bioenergy quantification}

The economic biomass availability refers to the quantity of woodchips from accessible areas characterised by an economically feasible bioenergy chain. This definition implies that only areas with positive net revenues are considered.

Total revenues are estimated as the sum of the production of different assortments (Bernetti et al. 2004). More than one component can, in fact, be produced in a forest stand (e.g., roundwood, timber poles, woodchips).

The revenues $R$ obtained from the $i$-th pixel are calculated as (eqn. 1):

$$
R_{i}=\sum_{a=1}^{n}\left(Y_{i} \cdot P_{a, i} \cdot p_{a}\right)
$$

where $n$ is the number of $a$ assortments in pixel $i ; Y_{\mathrm{i}}$ is the total yield in pixel $i ; P_{\mathrm{a}, \mathrm{i}}$ is the percentage of $a$-th assortment in pixel $i$; $p_{\text {a }}$ market price for $a$-th assortment. 
For the $v$-th process phase and $i$-th forest pixel, the processing costs $K_{\mathrm{P}}$ were calculated as (eqn. 2):

$$
K_{P, v, i}=\frac{k_{h, v, i}}{p_{v, i}} \cdot Y_{i}
$$

where $k_{\mathrm{h}, \mathrm{v}, \mathrm{i}}$ is the hourly cost for $v$-th process phase in $i$-th forest pixel; $p_{v, i}$ is the hourly productivity for $v$-th process phase in $i$-th forest pixel; $Y_{\mathrm{i}}$ yield for $i$-th forest pixel.

The hourly cost includes the machine and worker costs (see Appendix 1 - Tab. S1). The machine expense calculation are based on Miyata's methodology (1980). For each phase of the process, Biomasfor computes the hourly productivity based on the slope, tree characteristics, prescribed yield and extraction/transport distance (see Appendix 1, Tab. S2 - Stampfer \& Steinmüller 2001, Spinelli et al. 2007, Lubello 2008, Nakagawa et al. 2010, Spinelli \& Magagnotti 2010). The delay times are also computed.

The direction expenses $D_{\mathrm{i}}$, administrative costs $A d_{\mathrm{i}}$ and interests $I_{\mathrm{i}}$ are calculated (Bernetti \& Romano 2007) to define the total $\operatorname{cost} K_{\mathrm{T}, \mathrm{i}}$ (eqn. 3).

$$
K_{T, i}=K_{P, v, i}+D_{i}+A_{d i}+I_{i}
$$

Finally, the total economic bioenergy $Y_{\mathrm{E}}$ is expressed by eqn. 4 :

$$
Y_{E}=\sum_{i=1}^{h} Y_{T, i} \forall i \in\left(R_{i}-K_{T, i}>0\right)
$$

where $Y_{\mathrm{T}, \mathrm{i}}$ is the ecological biomass availability in $i$-th forest pixel, and $h$ is the total forest pixels in study area.

To include the cost of moving machinery, the concept of "minimum harvestable volume" developed by Lubello (2008) is considered. This concept involves the recognition that the harvesting of "small forest areas" with highly mechanized processes can fail to be economically feasible. For this reason, the authors calculate the break-even point (minimum harvestable volume) based on the total fixed costs of the machinery and the market price of the biomass components (eqn. 5):

$$
V_{\text {min }} \cdot P_{l}=F C_{m} \rightarrow V_{\text {min }}=\frac{F C_{m}}{P_{l}}
$$

where $V_{\min }$ is the minimum harvestable volume $\left(\mathrm{m}^{3}\right), P_{1}$ is the price at landing $\left(€ / \mathrm{m}^{3}\right)$ and $F C_{\mathrm{m}}$ is the fixed costs of machinery $(€)$.

The minimum harvestable area can be obtained using the average prescribed yield per unit of surface $\left(\right.$ e.g., $\left.\mathrm{m}^{3} / \mathrm{ha}\right)$.

\section{Sustainable bioenergy quantification}

Biomass removal causes the potential depletion of a forest ecosystem but also allows potential enhancement. Biomasfor can estimate the decrease in the economic bioenergy availability to avoid a potential negative impact on the forest system and can also esti- mate the improvement in the social and environmental components due to the positive influences of biomass removal.

The non-living biomass that remains in the forest after harvesting operations is very relevant in terms of habitat and biodiversity conservation. Deadwood provides many important components of wildlife habitat and is important for seeds and other organisms, such as wood-inhabiting fungi (Sullivan et al. 2011).

From the perspective of fertility, biomass removal can influence the nutrient capital of the forest soil, the nutrient status and the growth of trees (Wall \& Hytönen 2011). The literature review authored by Abbas et al. (2011) highlights the importance of the retention of tops and branches on the soil for hydrogeological protection and the maintenance of the carrying capacity of the site. In addition, water quality is influenced by soil compaction, which impacts water movement and increases surface runoff, erosion and the waterlogging of soil (Kraigher et al. 2002).

In this context, the following three indicators of negative impact are examined:

- site productivity reduction;

- soil and water protection reduction;

- biodiversity losses.

For each indicator and according to the local characteristics and the characteristics of mechanization, fixed biomass extraction limits were defined. Considerations of the maintenance of soil fertility yield removal li-

\begin{tabular}{|c|c|c|}
\hline $\begin{array}{l}\text { Multifunction } \\
\text { criterion }\end{array}$ & Variable & Description \\
\hline $\begin{array}{l}\text { Soil fertility } \\
\text { maintenance }\end{array}$ & Soil productivity & $\begin{array}{l}\text { Thinning: } 0 \% \text { on very low and low fertility } \\
\text { soils; } 70 \% \text { on other soils. } \\
\text { Final felling: } 90 \% \text { on all soils. }\end{array}$ \\
\hline \multirow[t]{4}{*}{$\begin{array}{l}\text { Soil and water } \\
\text { protection }\end{array}$} & Slope & $\begin{array}{l}\text { Maximum extraction rate: } 67 \% \text { of residues up } \\
\text { to } 30 \% \text { of slope and } 100 \% \text { over } 30 \% \text { and up } \\
\text { to } 100 \% \text { of slope. } 0 \% \text { over } 100 \% \text { of slope. }\end{array}$ \\
\hline & Soil depth & $\begin{array}{l}\text { Maximum extraction rate: } 0 \% \text { of residues on } \\
\text { superficial soils. }\end{array}$ \\
\hline & Soil texture & $\begin{array}{l}\text { Maximum extraction rate: } 0 \% \text { of residues on } \\
\text { compacted soils. }\end{array}$ \\
\hline & Soil compaction risk & $\begin{array}{l}\text { Maximum extraction rate: } 0 \% \text { of residues on } \\
\text { soil with very high compaction risk; } 25 \% \text { on } \\
\text { soil with high compaction risk. }\end{array}$ \\
\hline $\begin{array}{l}\text { Biodiversity } \\
\text { maintenance }\end{array}$ & Protected areas & $\begin{array}{l}\text { Maximum extraction rate: } 0 \% \text { of residues in } \\
\text { protected areas. }\end{array}$ \\
\hline $\begin{array}{l}\text { Fire risk } \\
\text { reduction }\end{array}$ & Fire risk index & $\begin{array}{l}\text { Fire risk index was normalised on maximum } \\
\text { single Country value (linear normalisation in } \\
\text { the range } 0-1 \text { ). No biomass removal limits } \\
\text { were set for fire risk reduction. }\end{array}$ \\
\hline $\begin{array}{l}\text { Touristic-recreational } \\
\text { valorization }\end{array}$ & Touristic value & $\begin{array}{l}\text { No biomass removal limits were set for tour- } \\
\text { istic-recreational valorization. }\end{array}$ \\
\hline $\begin{array}{l}\mathrm{CO}_{2} \text { emissions } \\
\text { reduction }\end{array}$ & $\begin{array}{l}\mathrm{CO}_{2} \text { emissions } \\
\text { calculated for each } \\
\text { forest process and } \\
\text { energy production }\end{array}$ & $\begin{array}{l}\text { No biomass removal limits were set for } \mathrm{CO}_{2} \\
\text { emissions reduction }\end{array}$ \\
\hline
\end{tabular}
mits based on the maximum rates for extracting stem and crown biomass during early

Tab. 2 - Extraction rate limits for multi-functionality criteria thinning (see the current and medium mobilization scenario by Verkerk et al. 2011). Soil fertility does not appear to be strongly influenced by the extraction of logging residues over the short term (Wall 2008); therefore, the removal of logging residues during final felling is permitted to a preset level of $90 \%$. From a perspective of soil and water protection, the extraction limits are based on the maximum rates of extraction of stem and crown biomass during early thinning and on logging residues resulting from final felling (see the current and medium mobilization scenario by Verkerk et al. 2011). In particular characteristics such as slope, soil depth, soil texture and soil compaction risk were included in the analysis (Tab. 2). Restrictions on biomass removal to facilitate the maintenance of biodiversity are based on information in Sullivan et al. (2011) and in Verkerk et al. (2011) that generally favors the avoidance of residues removal from protected areas.

Finally, three indicators of positive impact are evaluated:

- fire risk prevention

- touristic-recreational function improvement

- carbon dioxide emissions reduction.

According to forest typology, vegetation condition and climatic parameters, wood residues can represent a factor of risk for forest fires (Stupak et al. 2010). The removal of woody debris and thinning material is, thus, a potential method of fire prevention (Soliño et al. 2010). 
The evaluation of fire risk prevention is based on the fire risk index calculated for EU countries (Schelhaas et al. 2010). As stated by Schelhaas et al. (2010) the risk of fire depends on different aspects of the danger associated with a fire (the moisture content of forest fuel, the rate of spread, the weight of fuel consumed and the intensity of the fire). Thus, it is difficult to relate biomass removal to reductions in the fire risk index. Agee \& Skinner (2005) assess the principles of fire resistance for dry forests in terms of the following factors: (i) reductions in the amount of surface fuel; (ii) increases in the height of the living crown; (iii) decreases in the density of the crown; and (iv) retaining large trees belonging to resistant species. Each of these principles is strictly dependent on local forest and geomorphological conditions. For the Italian conditions, due to the absence of specific studies, a weight equal to $30 \%$ has been assigned to biomass removal performed to reduce the fire risk index (see Tab. 2)

Scenic beauty, landscape variability and suitability of forest for recreational activity can be improved by extraction of afterfelling residues (Tahvanainen et al. 2001, Gundersen \& Frivold 2008). For example, Ribe (1989) stresses slash removal to be an important post-harvest practice in increasing beauty perception of tourists. Thus, $100 \%$ of residues extraction is hypothesized in order to strengthen, recreational function. Touristic improvement was measured as the sum of forest surface, with double function (productive and touristic), that have an economically feasible bioenergy production process.

An additional potential positive impact resulting from forest biomass use is the reduction of GHG emissions. In this framework, Biomasfor computes $\mathrm{CO}_{2}$ emissions for the whole forest process, the avoidance of $\mathrm{CO}_{2}$ emissions through the use of alternative fossil fuel and the resulting net balance. To develop a precautionary analysis, the total forest processing emissions are considered, not only the emissions associated with biomass production (chipping and woodchip transport). The net balance of the $\mathrm{CO}_{2}$ emissions is estimated in comparison with the equivalent energy of fossil fuels potentially used for heating. The fossil fuel emission coefficients are based on the literature (Francescato \& Antonini 2010), with the assumption that bioenergy and fossil fuel heating plants (diesel oil plants) are equally efficient. The coefficients inserted in the model for $\mathrm{CO}_{2}$ computation for each forest process are shown in Appendix 1, Tab. S3 (Piegai 2000, Moscatelli et al. 2007, Karjalainen et al. 2001, Kilpeläinen et al. 2011).

The details of the limits on residue extraction for each forest multi-functionality parameter are shown in Tab. 2.
Tab. 3 - Dataset implemented for the case study.

\begin{tabular}{ll}
\hline Variable & Source \\
\hline DTM & Territorial Informative System (SIAT), Province of Trento \\
Main roads & Technical map, Province of Trento \\
Forest roads & Forest and Fauna Office (2010), Province of Trento \\
Total yield & Forest Management Plan (PEFO), Province of Trento \\
Yield per forest typology & Forest Management Plan (PEFO), Province of Trento \\
Forest management & Forest Management Plan (PEFO), Province of Trento \\
District Heating Plants (DHP) & Casini et al. (2012) \\
Forest treatment & Forest Management Plan (PEFO), Province of Trento \\
Compartments & Forest Management Plan (PEFO), Province of Trento \\
Roughness & Forest Management Plan (PEFO), Province of Trento \\
Lakes & Technical map, Province of Trento \\
Rivers & Technical map, Province of Trento \\
Mean tree diameter & Forest Management Plan (PEFO), Province of Trento \\
Mean tree volume & Forest Management Plan (PEFO), Province of Trento \\
Provincial boundary & ISTAT (http://www.istat.it) \\
Energy demand in DHP & Casini et al. (2012) \\
Soil productivity & Forest Management Plan (PEFO), Province of Trento \\
Soil texture & Forest Management Plan (PEFO), Province of Trento \\
Soil depth & Forest Management Plan (PEFO), Province of Trento \\
Soil compaction risk & Houšková (2010) \\
Fire risk index & Schelhaas et al. (2010) \\
Protected areas & Portale Cartografico Nazionale (http://www.pcn.minambi- \\
Touristic value & ente.it/PCNDYN/catalogowms.jsp?lan=it) \\
\hline & Forest Management Plan (PEFO), Province of Trento \\
\hline
\end{tabular}

\section{Case study}

The study area is the Province of Trento in the northeastern Italian Alps. The territory is characterized by strong variability in forest species composition and geomorphological conditions. These characteristics allow testing of the Biomasfor model in a widely differentiated area to include the variables that primarily influence biomass production. In addition, the demand for wood energy has been increasing rapidly in this area (Zambelli et al. 2012), and new tools are needed to assess the agroenergy chain and to quantify the supply of forest biomass.

\section{Dataset and scenario assessment}

The implementation of the dataset considers the sources for the variables listed in Tab. 3.

The model outputs are based on scenario analysis (a base scenario and a three-variation scenario) with a spatial resolution of 40x40 m.

The analysis is initially focused on high forest because residue removal is more convenient in this forest type than in coppices, and because high forest is important in the entire forest chain in the Province of Trento. The structure of the Forest Management Plan (PEFO) database does not allow the estimation of the spatial distribution of thinning material but only includes the biomass from final felling. Woody material extraction has been initially hypothesized to occur via the nearest forest road because of the absence of a complete map of landing sites.

The percentage of tops and branches in varies between 10 and $30 \%$ of the cormometric volume, depending on the specific harvesting interventions and forest characteristics (Spinelli \& Magagnotti 2007, Bernetti $\&$ Fagarazzi 2003). These values correspond to a range of $0.2-0.59 \mathrm{MWh} / \mathrm{m}^{3}$ of prescribed yield for a biomass moisture content of $40 \%$ (M40: current commercial moisture content). A cautionary value of $0.3 \mathrm{MWh} / \mathrm{m}^{3}$ is set in the base scenario. The available mechanization level and a short-term increase in this level suggest the use of a skidder for groundbased extraction and of a medium-power cable crane system for aerial extraction.

The calculation of revenues is based on the unit prices for each forest category (firs, larix, Mountain pines, Arolla pine, beech and other broadleaves) and the typology of assortments (unique assortment, Arolla pine stem, shorts, packaging wood, first-class sawlog, larix first-class sawlog, timber pole, prices are reported in the database of the Chambers of Commerce, Industry, Handcraft and Agriculture of the Province of Trento (CCIAA 2012) and refer to logs at the landing site. The base scenario biomass price is equal to $19.50 € / \mathrm{MWh}$, corresponding to approximately $55 € / \mathrm{t}$ (the average market price for M40 woodchips).

The ecological, technical and economic vahigh forest under Italian conditions usually short sawlog, sawlog, larix sawlog). Market lues used for scenario assessment are shown 
Tab. 4 - Parameters for the scenario assessment. (*): variation in respect to the base scenario.

\begin{tabular}{|c|c|c|c|c|c|c|}
\hline \multirow[b]{2}{*}{ 赵 } & \multirow{2}{*}{ 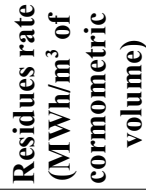 } & \multicolumn{4}{|c|}{ Extraction limits } & \multirow[b]{2}{*}{$\sum^{0}$} \\
\hline & & Machinery & 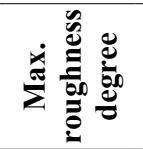 & 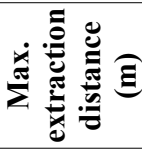 & $\frac{\ddot{a}}{\omega} \frac{\varrho}{\varrho}$ & \\
\hline \multirow[t]{2}{*}{ Base } & 0.3 & Medium power cable crane & No limits & 800 & $30.1-100$ & 19.5 \\
\hline & & Skidder & $0-1$ & 600 & $0-30$ & \\
\hline \multirow[t]{2}{*}{ A } & $0.49 *$ & Medium power cable crane & No limits & 800 & $30.1-100$ & 19.5 \\
\hline & & Skidder & $0-1$ & 600 & $0-30$ & \\
\hline \multirow[t]{2}{*}{ B } & 0.3 & High power cable crane* & No limits & $1200 *$ & $30.1-100$ & 19.5 \\
\hline & & Forwarder* & $0-1$ & $800 *$ & $0-30$ & \\
\hline \multirow[t]{2}{*}{$\mathrm{C}$} & 0.3 & Medium power cable crane & No limits & 800 & $30.1-100$ & $28.4^{*}$ \\
\hline & & Skidder & $0-1$ & 600 & $0-30$ & \\
\hline
\end{tabular}

in Tab. 4. In summary, variation is implemented in the following scenarios:

- scenario A: ecological parameter variation (increase in biomass extraction from 15 to $25 \%$ of cormometric volume for tops and branches);

- scenario B: technical parameter variation (increase in mechanization level using higher-power machinery characterized by higher hourly cost (Tab. S1), higher productivity (Tab. S2) and capable of a greater extraction distance);

- scenario $\mathrm{C}$ : economic parameter variation (increase in the sales price of biomass according to current market trends).

For each scenario, the ecological, technical and economic bioenergy availability are calculated. The provincial wood-energy supply/ demand ratio and the total net revenues for the entire forest chain are then quantified. Finally, the sustainable availability and the influence of biomass production on net $\mathrm{CO}_{2}$ emissions, fire risk reduction and recreational improvement are estimated.

\section{Results and discussion}

The results of scenario assessments are

Tab. 5 - Results os the four scenario assessments considered in the case study.

\begin{tabular}{lrrrr}
\hline Parameter & $\begin{array}{r}\text { Base } \\
\text { scenario }\end{array}$ & $\begin{array}{r}\text { Scenario } \\
\text { A }\end{array}$ & $\begin{array}{r}\text { Scenario } \\
\text { B }\end{array}$ & $\begin{array}{c}\text { Scenario } \\
\text { C }\end{array}$ \\
\hline Ecological availability $(\mathrm{MWh} / \mathrm{y})$ & 133596 & 218207 & 133596 & 133596 \\
Technical availability $(\mathrm{MWh} / \mathrm{y})$ & 121387 & 198266 & 123781 & 121387 \\
Economic availability $(\mathrm{MWh} / \mathrm{y})$ & 92058 & 156937 & 88529 & 95042 \\
Total revenues $(€ / \mathrm{y})$ & 6201907 & 7329056 & 5912112 & 7001438 \\
Energy demand in DHP $(\mathrm{MWh} / \mathrm{y})$ & & & & 178198 \\
Fertility bioenergy $(\mathrm{MWh} / \mathrm{y})$ & 82853 & 141243 & 79676 & 85538 \\
Soil and water protection bioenergy $(\mathrm{MWh} / \mathrm{y})$ & 70562 & 120179 & 67730 & 72803 \\
Biodiversity bioenergy $(\mathrm{MWh} / \mathrm{y})$ & 77160 & 131139 & 74160 & 79494 \\
Sustainable availability $(\mathrm{MWh} / \mathrm{y})$ & 53820 & 91342 & 51737 & 55395 \\
Net avoided emission $(\mathrm{t} \mathrm{CO} / \mathrm{y})$ & 23575 & 44046 & 23288 & 24315 \\
Fire risk (absolute value) & & & & 938070 \\
Reduced fire risk & 896873 & 894674 & 898633 & 895253 \\
(absolute value and \%) & $(4.39 \%)$ & $(4.63 \%)$ & $(4.20 \%)$ & $(4.56 \%)$ \\
Recreational area (ha) & 98707 & 98707 & 98707 & 98707 \\
Improved recreational area $(\mathrm{ha})$ & 40214 & 41903 & 39251 & 41471 \\
\hline
\end{tabular}

sity is greater than $20 \mathrm{~m}$ per hectare is generally considered highly accessible (Hippoliti \& Piegai 2000).

The use of wood residues for thermal energy production potentially prevents the emission of $23500 \mathrm{t} \mathrm{CO} / \mathrm{y}$. Biomass removal results in a low percentage of fire risk reduction (about 4\%) due to local characteristics that produce a fire risk index lower than the national mean value. A total of $41 \%$ of the productive forest area is characterized by touristic-recreational improvement.

The scenario analysis shows an increase of the economic availability in Scenario A and in Scenario C ( $+3 \%$ and $+2 \%$, respectively). Scenario B appears less attractive than the base scenario $(-3 \%)$ because the greater extraction distance and greater productivity of the hypothetical machinery cannot compensate for the higher hourly costs. In this case, the rate of biomass removal influences the outcome. For example, increasing the extraction of tops and branches from $15 \%$ of the cormometric volume to $22 \%$ produces an enhancement of economic efficiency equal to a $7 \%$ gain relative to the base scenario.

An additional important result is the halving of carbon dioxide emissions and the doubling of sustainable availability in Scenario $\mathrm{A}$. The variation in the other parameters in Scenarios B and C is quite low.

The wood-energy supply/demand ratio considers the demand associated with the District Heating Plants (DHPs) of the Province of Trento (Casini et al. 2012). This ratio varies between 0.5 in Scenario B and 0.88 in Scenario A. Although the total demand is not satisfied by forest residues, it must be recognized that the main source of bioenergy for the DHPs is currently the sawmill residues (approximately 80\%). Forest biomass can represent an integration of sawmill residues. Furthermore, biomass from thinning should be included in the forest energy chain assessment.

Finally, the biomass allotted to local residents for their residence rights should be excluded from the total bioenergy availability (Zambelli et al. 2012). The total amount of residues allotted to the residents is 68000 MWh/y (Forest and Fauna Office 2010).

\section{Potential future improvements and conclusions}

The model developed in this study appears to be an appropriate DSS tool for the quantification of forest bioenergy availability. The multistep procedure yields an estimate of biomass for energy production that introduces ecological, technical, economic and social constraints based on a literature analysis and on local characteristics. The spatially based outputs allow the results to be identified in a georeferenced format and the values of the areas analyzed to be aggregated at the desired administrative level. This as- 
pect should be particularly relevant for policymakers, allowing them to apply regulations and funds at the local level. The flexible structure of the tool allows its use in different study areas and for different available dataset. The implementation of the model in a single software system (GRASS GIS) facilitates the installation and management.

The scenario assessment framework defines not only the amount of biomass but also the supply/demand ratio and the economic added value for the entire forest chain according to the modeling of the input variables. The potential impact of the removal of woody residues is estimated both in negative terms and for environmental enhancement.

The term "holistic model" applied to Biomasfor does not mean that the results obtained are claimed to be exhaustive. Rather, the structure of the model and the opensource basis of the approach furnish the opportunity to develop further evaluations for each parameter. In particular, multifunctionality variables could be examined in depth and new input data introduced (e.g., additional forest production processes and functions such as new mechanization levels, impact analysis of regeneration or berry production). Field experiments now in progress will help verify the correspondence between real forest processes and the model outputs. Best practices and trade-off among different forest function could be evaluated by the application of multicriteria approach and the depiction of Pareto front and manifolds.

Future case studies could be performed with coppices and different forest treatments (final felling and thinning) to delineate not only the total amount of bioenergy but also the qualitative characteristics resulting from the origin of the biomass (e.g., stems, tops, branches, conifers, broadleaved species). This categorization will allow the quantification of biomass suitable for heating plants of different sizes and power characteristics.

To optimize the functionality of the model, the transport distances for woody material could be computed on the basis of the true demand/supply ratio for the DHPs or the biomass logistic centers. In the current version of Biomasfor, these distances represent the nearest collection points to the forest area. The application of GIS-based linear programming (LP) methodologies could overcome this limitation. The implementation of a user-friendly graphical interface will facilitate the application of the model by its end users. This work is based on a holistic concept that can be adopted in other fields of application following the same logic (Rada et al. 2012).

The Biomasfor model is available online for testing and integration at http://sourceforge.net/p/biomasfor/code/ci/415ab11cda6fae799d77423a8cb400af780f9f09/tree/.

\section{Acknowledgments}

This work was funded by the BIOMASFOR project co-funded by the CARITRO Foundation through grant No. 101. The authors wish to acknowledge CARITRO, as well as the BIOMASFOR project partners, for their contribution to the research.

\section{References}

Abbas D, Current D, Phillips M, Rossman R, Hoganson H, Brooks KN (2011). Guidelines for harvesting forest biomass for energy: a synthesis of environmental considerations. Biomass and Bioenergy 35: 4538-4546. - doi: 10.1016/j.biombioe.2011.06.029

Agee JK, Skinner CN (2005). Basic principles of forest fuel reduction treatments. Forest Ecology and Management 211: 83-96. - doi: 10.1016/j.foreco.2005.01.034

Aguilar FX (2009). Spatial econometric analysis of location drivers in a renewable resources-based industry: the U.S. South Lumber Industry. Forest Policy and Economics 11: 184193. - doi: 10.1016/j.forpol.2009.02.006

Aherne J, Posch M, Forsius M, Lehtonen A, Härkönen K (2012). Impacts of forest biomass removal on soil nutrient status under climate change: a catchment-based modelling study for Finland. Biogeochemistry 107: 471-488. - doi: 10.1007/s10533-010-9569-4

Angelis-Dimakis A, Biberacher M, Dominguez J, Fiorese G, Gadocha S, Gnansounou E, Guariso G, Kartalidis A, Panichelli L, Pinedo I, Robba M (2011). Methods and tools to evaluate the availability of renewable energy sources. Renewable and Sustainable Energy Reviews 15: 1182-1200. - doi: 10.1016/j.rser.2010.09.049

Aosić B, Stanić Z, Duić N (2011). Geographic distribution of economic potential of agricultural and forest biomass residual for energy use: case study Croatia. Energy 36: 2017-2028. - doi: 10.1016/j.energy.2010.10.009

Berg S, Fischbach J, Bruchert F, Poissonnet M, Pizzirani S, Varet A, Sauter UH (2012). Towards assessing the sustainability of European logging operations. European Journal of Forest Research 131: 81-94. - doi: 10.1007/s10342-011-0561-x Bernetti I, Fagarazzi C (2003). BIOSIT: una metodologia GIS per lo sfruttamento efficiente e sostenibile della "risorsa biomassa" a fini energetici. Centro Stampa 2P, Pontassieve, Firenze, Italy, pp. 141-167. [in Italian]

Bernetti I, Romano S (2007). Economia delle risorse forestali - vol II. Liguori editore, Napoli, Italy, pp. 340-355. [in Italian]

Bernetti I, Fagarazzi C, Fratini R (2004). A methodology to analyse the potential development of biomass-energy sector: an application in Tuscany. Forest Policy and Economics 6: 415432. - doi: 10.1016/j.forpol.2004.03.018

Bush G (2012). GIS-based tools for regional assessments and planning processes regarding potential environmental effects of poplar SRC. Bioenergy Research 5: 584-605. - doi: 10.1007/ s12155-012-9224-0

Calvert K (2011). Geomatics and bioenergy fea- sibility assessments: taking stock and looking forward. Renewable and Sustainable Energy Reviews 15: 1117-1124. - doi: 10.1016/j.rser.2010. 11.014

Casini L, De Meo I, Paletto A, Sacchelli S (2012). Cippato Trentino - Alcune risposte dal Progetto Biomasfor. Terra Trentina 1: 16-18. [in Italian]

CCIAA (2012). Legno Trentino - Economia e mercato. Chambers of Commerce, Industry, Handcraft and Agriculture, Trento, Italy. [online] URL: http://www.legnotrentino.it

Chirici G, Barbati A, Maselli F (2007). Modelling of Italian forest net primary productivity by the integration of remotely sensed and GIS data. Forest Ecology and Management 246: 285-295. doi: 10.1016/j.foreco.2007.04.033

Cornelissen S, Koper M, Deng YY (2012). The role of bioenergy in a fully sustainable global energy system. Biomass and Bioenergy 41: 2133. - doi: 10.1016/j.biombioe.2011.12.049

Eisenbies MH, Vance ED, Aust WM, Seiler JR (2009). Intensive utilization of harvest residues in southern pine plantations: quantities available and implications for nutrient budgets and sustainable site productivity. Bioenergy Research 2 : 90-98. - doi: 10.1007/s12155-009-9036-Z

Fiorese G, Guariso G (2010). A GIS-based approach to evaluate biomass potential from energy crops at regional scale. Environmental Modelling and Software 25: 702-711. - doi: 10.1016/j. envsoft.2009.11.008

Forest Energy Portal (2012). Supply chain illustrations. [online] URL: http://www.forestenergy. org/pages/images/

Francescato V, Antonini E (2010). La combustione del legno. Fattori di emissione e quadro normativo. Veneto Agricoltura, Azienda Regionale per i Settori Agricolo, Forestale e Agroalimentare, Settore Bioenergie e Cambiamento Climatico, Legnaro, PD, Italy. [in Italian]

Freppaz D, Minciardi R, Robba M, Rovatti M, Sacile R, Taramasso A (2004). Optimizing forest biomass exploitation for energy supply at a regional level. Biomass and Bioenergy 26: 15-25. doi: 10.1016/S0961-9534(03)00079-5

Frombo F, Minciardi R, Robba M, Sacile R (2009). A decision support system for planning biomass-based energy production. Energy 34: 362-369. - doi: 10.1016/j.energy.2008.10.012

Gallaun H, Zanchi G, Nabuurs GJ, Hengeveld G, Schardt M, Verkerk PJ (2010). EU-wide maps of growing stock and above-ground biomass in forests based on remote sensing and field measurements. Forest Ecology and Management 260: 252-261. - doi: 10.1016/j.foreco.2009.10.011

Gobattoni F, Pelorosso R, Lauro G, Leone A, Monaco R (2011). A procedure for mathematical analysis of landscape evolution and equilibrium scenarios assessment. Landscape and Urban Planning 103: 289-302. - doi: 10.1016/j.landurbplan.2011.08.011

Gundersen VS, Frivold LH (2008). Public preferences for forest structures: a review of quantitative surveys from Finland, Norway and Sweden. Urban Forestry and Urban Greening 7: 241-258. - doi: 10.1016/j.ufug.2008.05.001 
Hippoliti G, Piegai F (2000). La raccolta del legno. Tecniche e sistemi di lavoro. Compagnia delle Foreste, Arezzo, Italy. [in Italian]

Houšková B (2010). Soils susceptibility to compaction. Web site. [online] URL: http://eusoils.jrc.ec.europa.eu/library/themes/compaction/ Karjalainen T, Zimmer B, Berg S, Welling J, Schwaiger H, Finér L, Cortijo P (2001). Energy, carbon and other material flows in the life cycle assessment of forestry and forest products. Discussion Paper no. 10, European Forest Institute, Joenssu, Finland, pp. 44.

Kilpeläinen A, Alam A, Strandman H, Kellomäki S (2011). Life cycle assessment tool for estimating net $\mathrm{CO}_{2}$ exchange of forest production. Global Change Biology Bioenergy 3: 461-471. doi: 10.1111/j.1757-1707.2011.01101.x

Kotamaa E, Tokola T, Maltamo M, Packalén P, Kurttila M, Mäkinen A (2010). Integration of remote sensing-based bioenergy inventory data and optimal bucking for stand-level decision making. European Journal of Forest Research 129: 875886. - doi: 10.1007/s10342-010-0357-4

Kraigher H, Jurc D, Kalan P, Kutnar L, Levanic T, Rupel M, Smolej I (2002). Beech coarse woody debris characteristics in two virgin forest reserves in southern Slovenia. Zbornik gozdarstva in lesarstva 69: 91-134.

Lasserre B, Chirici G, Chiavetta U, Grafî V, Tognetti R, Drigo R, Di Martino P, Marchetti M (2011). Assessment of potential bioenergy from coppice forests trough the integration of remote sensing and field surveys. Biomass and Bioenergy 35: 716-724. - doi: 10.1016/j.biombioe.2010. 10.013

Lopez-Rodrìguez F, Pérez Atanet C, Cuadros Blazquez F, Ruiz Celma A (2009). Spatial assessment of the bioenergy potential of forest residues in the western province of Spain, Caceres. Biomass and Bioenergy 33: 1358-1366. - doi: 10.1016/j.biombioe.2009.05.026

Lubello D (2008). A rule-based SDSS for integrated forest harvesting planning. $\mathrm{PhD}$ thesis, $\mathrm{Fa}-$ culty of Agriculture, University of Padua, Italy, pp. 91-104.

Lubello D, Del Favero A, Cavalli R (2008). Un metodo tecnico-economico come ausilio alla determinazione della ripresa. L'Italia Forestale e Montana 3: 225-240. [in Italian]

Masera O, Ghilardi A, Drigo R, Trossero MA (2006). WISDOM: a GIS-based supply demand mapping tool for woodfuel management. Biomass and Bioenergy 7: 618-637. - doi: 10.1016 j.biombioe.2006.01.006

Miyata ES (1980). Determining fixed and operating costs of logging equipment. Gen.Tech.Rep. GTR NC-55, Northcentral Forest Experiment Station, USDA Forest Service, St. Paul, MN, USA, pp. 16.

Moller B, Nielsen PS (2007). Analysing transport cost of Danish forest wood chip resources by means of continuous cost surfaces. Biomass and Bioenergy 31: 291-298. - doi: 10.1016/j.biombioe.2007.01.018

Moscatelli M, Pettenella D, Spinelli R (2007). Productivity and costs of fully mechanized har- vesting in Italian Appenines' chestnut coppices. Forest@ 4: 51-59. - doi: 10.3832/efor04370040051 [in Italian with English abstract]

Nakagawa M, Hayashi N, Narushima T (2010). Effect of tree size on time of each work element and processing productivity using an excavatorbased single-grip harvester or processor at a landing. Journal of Forest Research 15: 226-233. - doi: 10.1007/s10310-010-0180-2

Neteler M, Bowman MH, Landa M, Metz M (2012). GRASS GIS: A multi-purpose open source GIS. Environmental Modelling and Software 31: 124-130. - doi: 10.1016/j.envsoft.2011. 11.014

Notaro S, Paletto A (2011). Links between mountain communities and environmental services in the Italian Alps. Sociologia Ruralis 51: 137-157. - doi: 10.1111/j.1467-9523.2011.00532.x

Panichelli L, Gnansounou E (2008). GIS-based approach for defining bioenergy facilities location: a case study in Northern Spain based on marginal delivery costs and resources competition between facilities. Biomass and Bioenergy 32: 289-300. - doi: 10.1016/j.biombioe.2007.10. 008

Piegai F (2000). I consumi di combustibili nei lavori forestali. Sherwood 62: 31-32. [in Italian]

Forest and Fauna Office (2010). Document for the quantification of biomass for resident rights. Province of Trento, Trento, Italy. [in Italian]

Rada EC, Ragazzi M, Brini M, Marmo L, Zambelli P, Chelodi M, Ciolli M (2012). Perspectives of low-cost sensors adoption for air quality monitoring. UPB Scientific Bulletin, Series D, Mechanical Engineering 74 (2): 243-250.

Raison RJ (2002). Environmental sustainability of forest energy production. In: "Bioenergy from Sustainable Forestry" (Richardson J, Björheden R, Hakkila P, Lowe AT, Smith CT eds). Guiding Principles and Practice, Forestry Sciences 71: 159-263. - doi: 10.1007/0-306-47519-7_5

Ramachandra TV (2009). RIEP: regional integrated energy plan. Renewable and Sustainable Energy Reviews 2: 285-317. - doi: 10.1016/j.rser. 2007.10.004

Rettenmaier N, Reinhardt G, Schorb A, Köppen S, Von Falkenstein E, Chalmers GB et al. (2008). Status of biomass resource assessments - version 1. FELIS - Department of Remote Sensing and Landscape Information Systems, University of Freiburg, Germany.

Ribe RG (1989). The aesthetics of forestry: what has empirical preference research taught us? Environmental Management 13: 55-74. - doi: 10.1007/BF01867587

Riffell S, Verschuyl J, Miller D, Wigley TB (2011). Biofuel harvests, coarse woody debris, and biodiversity - a meta-analysis. Forest Ecology and Management 261: 878-887. - doi: 10.1016/j.foreco.2010.12.021

Sacchelli S, Fagarazzi C, Bernetti I (2013a). Economic evaluation of forest biomass production in central Italy: a scenario assessment based on spatial analysis tool. Biomass and Bioenergy 53:110. - doi: 10.1016/j.biombioe.2012.11.026 Sacchelli S, De Meo I, Paletto A (2013b). Bio- energy production and forest multifunctionality: a trade-off analysis using multiscale GIS model in a case study in Italy. Applied Energy 104: 1020. - doi: 10.1016/j.apenergy.2012.11.038

Schelhaas MJ, Hengeveld G, Moriondo M, Reinds GJ, Kundzewicz ZW, ter Maat $\mathrm{H}$, Bindi M (2010). Assessing risk and adaptation options to fires and windstorms in European forestry. Mitigation and Adaptation Strategies for Global Change 15: 681-701. - doi: 10.1007/s11027-010 $-9243-0$

Soliño M, Prada A, Vazquez MX (2010). Designing a forest-energy policy to reduce forest fires in Galicia (Spain): a contingent valuation application. Journal of Forest Economics 16: 217 233. - doi: 10.1016/j.jfe.2009.11.006

Sonneborn CL (2004). Renewable energy and market-based approaches to greenhouse gas reduction: opportunity or obstacle? Energy Policy 16: 1799-1805. - doi: 10.1016/S0301-4215(03) 00166-6

Spinelli R, Magagnotti N (2007). La produzione di biomassa legnosa nella selvicoltura alpina: quantità, sistemi di raccolta, costi. L'Italia Forestale e Montana 5/6: 421-435. [in Italian]

Spinelli R, Magagnotti N (2010). A tool for productivity and cost forecasting of decentralised wood chipping. Forest Policy and Economics 12: 194-198. - doi: 10.1016/j.forpol.2009.10.002

Spinelli R, Nati C, Magagnotti N (2007). Recovering logging residues: experiences from the Italian Eastern Alps. Croatian Journal of Forest Engineering 28: 1-9.

Stampfer K, Steinmüller T (2001). A new approach to derive a productivity model for the harvester "Valmet 911 Snake". In: Prooceedings of the "International Mountain Logging and 11th Pacific Northwest Skyline Symposium". Seattle (WA - USA) 10-12 December 2001. University of Washington, WA, USA, pp. 254-262.

Steinigera S, Hay GJ (2009). Free and open source geographic information tools for landscape ecology. Ecological Informatics 4: 183-195. - doi 10.1016/j.ecoinf.2009.07.004

Steubing B, Zah R, Waeger P, Ludwig C (2010). Bioenergy in Switzerland: assessing the domestic sustainable biomass potential. Renewable and Sustainable Energy Reviews 14: 2256-2265. doi: 10.1016/j.rser.2010.03.036

Stupak I, Lattimore B, Titus BD, Tattersall S (2010). Criteria and indicators for sustainable forest fuel production and harvesting: a review of current standards for sustainable forest management. Biomass and Bioenergy 35: 3287-3309. doi: 10.1016/j.biombioe.2010.11.032

Sullivan TP, Sullivan DS, Lindgren PMF, Ransome DB, Bull JB, Ristea C (2011). Bioenergy or biodiversity? Woody debris structures and maintenance of red-backed voles on clearcuts. Biomass and Bioenergy 35: 4390-4398. - doi: 10.1016/j.biombioe.2011.08.013

Tahvanainen L, Tyrväinen $\mathrm{L}$, Ihalainen $\mathrm{M}$, Vuorela N, Kolehmainen O (2001). Forest management and public perceptions - visual versus verbal information. Landscape and Urban Planning 53: 53-70. - doi: 10.1016/S0169-2046(00) 
00137-7

Tattoni C, Ciolli M, Ferretti F, Cantiani MG (2010). Monitoring spatial and temporal pattern of Paneveggio forest (Northern Italy) from 1859 to 2006. iForest - Biogeosciences and Forestry 3 (1): 72-80. - doi: 10.3832/ifor0530-003

Tattoni C, Ciolli M, Ferretti F (2011). The fate of priority areas for conservation in protected areas: a fine-scale Markov chain approach. Environmental Management 47 (2): 263-278. - doi: 10.1007/s00267-010-9601-4

Valente C, Spinelli R, Hillring BG (2011). LCA of environmental and socio-economic impacts related to wood energy production in alpine conditions: Valle di Fiemme (Italy). Journal of Cleaner Production 19: 1931-1938. - doi: 10.1016/j. jclepro.2011.06.026

Venema HD, Calamai PH (2003). Bioenergy systems planning using location-allocation and landscape ecology design principles. Annals of Operations Research 123: 241-264. - doi 10.1023/A:1026135632158

Verkerk PJ, Anttila P, Eggers J, Lindner M, Asikainen A (2011). The realisable potential supply of wood biomass from forests in the European Union. Forest Ecology and Management 261: 2007-2015. - doi: 10.1016/j.foreco. 2011.02 .027
Vettorato D, Geneletti D, Zambelli P (2011). Spatial comparison of renewable energy supply and energy demand for low-carbon settlements. Cities 28 (6): 557-566. - doi: 10.1016/j.cities. 2011.07.004

Voivontas D, Assimacopoulos D, Koukios EG (2001). Assessment of biomass potential for power production: a GIS based method. Biomass and Bioenergy 20: 101-112. - doi: 10.1016/ S0961-9534(00)00070-2

Wall A, Hytönen J (2011). The long-term effects of logging residue removal on forest floor nutrient capital, foliar chemistry and growth of a Norway spruce stand. Biomass and Bioenergy 35: 3328-3334. - doi: 10.1016/j.biombioe.2010.08. 063

Wall A (2008). Effect of removal of logging residue on nutrient leaching and nutrient pools in the soil after clearcutting in a Norway spruce stand. Forest Ecology and Management 256: 1372-1383. - doi: 10.1016/j.foreco.2008.06.044 Wang J, Chen J, Ju W, Li M (2010). IA-SDSS: A GIS-based land use decision support system with consideration of carbon sequestration. Environmental Modelling and Software 25 (4): 539-553. - doi: 10.1016/j.envsoft.2009.09.010

Zambelli P, Lora C, Ciolli M, Spinelli R, Tattoni C, Vitti A, Zatelli P (2010). A FOSS4G model to estimate forest exploitation methods and biomass availability for renewable energy production. In: Proceedings of "FOSS4G 2010". Barcelona (Spain) 6-9 September 2010, pp. 1-17. [online] URL: http://2010.foss4g.org/papers/3405.pdf Zambelli P, Lora C, Spinelli R, Tattoni C, Vitti A, Zatelli P, Ciolli M (2012). A GIS decision support system for regional forest management to assess biomass availability for renewable energy production. Environmental Modelling and Software 38: 203-213. - doi: 10.1016/j.envsoft. 2012. 05.016

\section{Supplementary Material}

\section{Appendix 1}

Tab. S1 - Definition of total hourly cost per forest process.

Tab. S2 - Definition of hourly productivity per forest process.

Tab. S3 - Definition of $\mathrm{CO}_{2}$ emissions per forest process.

Link: Sacchelli_897@supp1001.pdf 